\title{
Different degrees of malnutrition and immunological alterations according to the aetiology of cirrhosis: a prospective and sequential study
}

\author{
Wanda Regina Caly, Edna Strauss, Flair José Carrilho* and \\ Antonio Atílio Laudanna
}

Address: Department of Gastroenterology - University of São Paulo School of Medicine, Brazil

Email: Wanda Regina Caly - wanda.caly@bol.com.br; Edna Strauss - edna.strauss@hcnet.usp.br; Flair José Carrilho* - fjcarril@netpoint.com.br; Antonio Atílio Laudanna - laudanna@usp.br

* Corresponding author

Published: 07 October 2003

Received: 08 July 2003

Nutrition Journal 2003, 2:10

Accepted: 07 October 2003

This article is available from: http://www.nutritionj.com/content/2/I/I0

(C) 2003 Caly et al; licensee BioMed Central Ltd. This is an Open Access article: verbatim copying and redistribution of this article are permitted in all media for any purpose, provided this notice is preserved along with the article's original URL.

\begin{abstract}
Objectives: In this work we investigated how immunological dysfunction and malnutrition interact in alcoholic and viral aetiologies of cirrhosis.

Methods: To investigate the matter, 77 cirrhotic patients divided in three aetiologies [Alcohol, $\mathrm{HCV}$ and Alcohol $+\mathrm{HCV}$ ) and 32 controls were prospectivelly and sequentially studied. Parameters of humoral immunity (Components 3 and 4 of seric complement and immunoglobulins $A, M, G$ and $E$ ) and of cellular immunity (total leukocytes and lymphocytes in peripheral blood, $T$ lymphocytes subpopulations, CD4+ and CD8+, CD4+/CD8+ ratio and intradermic tests of delayed hypersensitivity), as well as nutrititional parameters: anthropometric measures, serum albumin and transferrin were evaluated.
\end{abstract}

Results: Multiple statistical comparisons showed that IgM was higher in HCV group; IgG was significantly elevated in both HCV and Alcohol + HCV, whereas for the Alcohol group, IgE was found at higher titles. The analysis of T- lymphocytes subpopulations showed no aetiologic differences, but intradermic tests of delayed hypersensitivity did show greater frequency of anergy in the Alcohol group. For anthropometric parameters, the Alcohol + HCV group displayed the lowest triceps skinfold whereas creatinine - height index evaluation was more preserved in the $\mathrm{HCV}$ group. Body mass index, arm muscle area and arm fat area showed that differently from alcohol group, the HCV group was similar to control.

Conclusion: Significant differences were found among the main aetiologies of cirrhosis concerning immunological alterations and nutritional status: better nutrition and worse immunology for $\mathrm{HCV}$ and vice-versa for alcohol.

\section{Background}

For many years malnutrition has been suggested as an important factor in the onset of alcoholic liver disease [1$3]$. The high incidence of cirrhosis and steatosis in desti- tute populations, the common malnutritional state of the alcoholics, the association between the severity of the alcoholic liver disease and the degree of malnutrition and the experimental production of steatosis and liver 
cirrhosis upon methyonine- and choline-depleted diets strongly support such correlation $[3,4]$.

On the one hand, malnutrition is worse in alcoholics from lower social classes, as a direct consequence of the poor nutritional condition [5]. On the other hand, it is well established that alcoholism, per se, is the main cause of malnutrition, even with an adequate alimentary supply, due to deficient food intake, anorexia, nausea and vomiting, poor gastrointestinal absorption, inadequate caloric and protein ingestion, alterations in the carbohydrate, protein and fat metabolism and rise in the energetic expenditure resulting from the occurrence of sepsis or ethanol in these patients $[6,7]$. Malnutrition is yet associated with worse clinical outcomes in cirrhotic patients - leading to complications such as ascites, encephalopathy, hepatorenal syndrome and diabetes [8], besides the association of worse malnutritional status with higher frequency of death $[9,10]$.

In our view $[10]$ and in the view of others $[11,12,1,13-$ $15]$, the cirrhotic patients who are more severely affected by malnutrition are more likely to present complications, such as infectious processes, presumably due to immunological deficiencies in the humoral and cellular responses. Since these alterations lead to an increase in the catabolism, which in turn aggravates malnutrition, a vicious circle is established [15]. As far as we know, nutritional and immunological alterations in cirrhosis due to HCV have not been addressed together. In fact, the great majority of the studies refer to the alcoholic but not to the viral aetiology of cirrhosis $[16,17]$.

To assess both nutritional and immunological alterations in HCV related cirrhotic patients in comparison to alcoholic cirrhosis and evaluate the alcohol and HCV associated group that is very frequent in the clinical practice were the main objectives of this study.

\section{Patients and Methods}

Seventy seven cirrhotic patients were prospective and consecutively studied, and were divided in three groups with respect to aetiology: 33 by alcohol (ALC), 20 by alcohol and HCV (ALC+HCV) and 24 by HCV (HCV) and 32 subjects were enrolled as controls.

Patients were from both genders, aged 18 - 65 years. The sex ratio varied among the three groups, being men more predominant in the groups with alcoholism and women more frequent in the HCV and control groups. The mean age was 52 years for the cirrhotic groups and 37.2 years for the control group. To validate the latter group as control, despite the difference in the mean age, a statistical analysis using age as co-variable was employed in the evaluation of all parameters; glycaemia was the only one to present a linear correlation with increasing age.

Cirrhotic patients were classified as Child-Pugh A and B, without ascite and/or edema upon physical and ultrasound examination. The control group included non-cirrhotic patients with dyspeptic complaints and for whom general evaluation, ultrasound and endoscopy, showed no alterations or enantematic gastritis only.

Concerning the epidemiological background, there was a higher prevalence of prior surgery $(75 \%)$ and transfusion (58.33\%) within the HCV groups, and no difference between the ALC and ALC+HCV regarding daily alcohol intake, years of consumption or abstinence period.

Patients who had a minimum pure ethanol intake of $80 \mathrm{~g} /$ day for at least 8 years were considered chronic alcohol drinkers. Note that patients from the HCV and control groups claimed either no alcohol intake or less than $10 \mathrm{~g} /$ day. All patients were inquired for risk factors of viral infections. Patients with associated chronic diseases were excluded (chronic renal failure, congestive heart failure, chronic pacreatitis), as so were those with any other disease leading to malnutrition or poor nutritional absorption, such as neoplasias and hepatocarcinoma. Patients with history of anti-viral treatment for HCV or HIV-positive were also excluded.

Serological detection of the hepatitis B and C viruses and HIV were performed with ELISA tests: second generation anti-HCV KIT from Abott and Ortho Diagnostics; anti$\mathrm{HBc}, \mathrm{HBs}$ Ag and anti-HIV from Abott.

All patients were submitted to hepatic function tests by monitoring the following markers: aspartate aminotransferase (AST), alanine aminotransferase (ALT), total bilirrubin, prothrombin time and activity (PTA), hemogram, platelets, seric iron, transferrin, alpha-fetoprotein and glycaemia. Liver biopsy was performed in all patients who had no blood dyscrasia $(75,32 \%)$ and no other contraindications. Clinical and biochemical criteria according to Garcia-Tsao et al (1985) were considered for diagnosis of hepatic cirrhosis in cases without liver biopsy.

Nutritional evaluation was based on the biochemical parameters - serum albumin and transferrin and anthropometric parameters - actual weight as a percentage of ideal body weight (\%IBW), body mass index (BMI), percentage of the standard value for triceps skinfold (\% TSF), arm muscle area (AMA), arm fat area (AFA), percentage of TSF and AMC depletion, besides creatinine-height index $(\mathrm{CHI})$. 
A single observer, applying the Frisancho rules $[19,20]$ performed the objective-nutritional evaluation. To estimate depletion percentile, the rules of Blackburn et al [21] were employed. The BMI was assessed as described by Heetderks [22]. The classification of the degree of malnutrition was based on the following studies: Blackburn and Thornton [23], Frisancho [19] and Heetderks [22].

The humoral-immunological alterations were evaluated by assessing serum immunoglobulins (A, M, G and E) and the complement - components' 3 and 4 by the Nephelometria methodology. Cellular immunity was evaluated by counting total lymphocytes in the automated counter Cell-Dyn 3000. The peripheral T-lymphocytes and subpopulations - $\mathrm{CD}^{+}$and $\mathrm{CD} 8{ }^{+}$were analysed by Flow Cytometry with triple-immunofluorescence staining; the monoclonal antibodies were obtained from Becton-Dickison kit and an Ortho-Diagnostic Cytometer. All patients were subjected to intradermal test for delayed hypersensitivity with the following antigens: purified protein derivative (PPD), candidin, trichophytin and dinitrochlorobenzene (DNCB); the injections were given in the forearm. After 48 hours, reactivity was analysed by measuring the formation of touchable nodules, considered positive if diameter was at least $5 \mathrm{~mm}$. The DNCB test was performed as described by Catalona et al, (1972).
The results of the intradermic tests were taken as immunocompetent, those with 2 or more positive tests, hypoergic, those with one positive test only, and anergic, those with no positive reactivity.

The protocol was previously approved by the Ethical Committee of the Hospital and all patients were aware of the research objectives and signed their informed consent.

\section{Statistical Analysis}

The Pearson's chi-square and Fisher's exact tests were applied to the four groups in the analysis of the qualitative variables. The remaining variables were initially compared by the univariate analysis ; and the variables belonging to the same class were further studied by the Pearson'scorrelation coefficient ( $\mathrm{r}$ ). Whenever correlation between two or more variables was significant, the multivariate analysis was applied further.

Groups were compared regarding their epidemiological data and variables from the groups, that showed significant differences were considered as co-variables. A logarithmic transformation was applied for non normal variable distributions.

Significance was accepted at the 5\% probability level ( $\alpha=$ 0.05 ) and the Statistical Analysis System (SAS) was employed in all statistical calculations.

Table I: Haematological and biochemical results with statistically significant differences in the four studied groups.

\begin{tabular}{|c|c|c|c|c|c|c|c|c|c|c|c|c|c|}
\hline \multirow[t]{2}{*}{ PARAMETERS } & \multicolumn{3}{|c|}{ ALCOHOL } & \multicolumn{3}{|c|}{$\mathrm{ALC}+\mathrm{HCV}$} & \multicolumn{3}{|c|}{$\mathrm{HCV}$} & \multicolumn{3}{|c|}{ CONTROL } & \multirow[t]{2}{*}{$P$} \\
\hline & $\mathrm{N}$ & $M$ & SD & $\mathrm{N}$ & $M$ & SD & $\mathrm{N}$ & $M$ & SD & $\mathrm{N}$ & $M$ & SD & \\
\hline Platelets $/ \mathrm{mm}^{3}$ & 33 & $174 \times 10^{3}$ & $83 \times 10^{3}$ & 20 & $149 \times 10^{3}$ & $59 \times 10^{3}$ & 24 & $127 \times 10^{3}$ & $70 \times 10^{3}$ & 32 & $260 \times 10^{3}$ & $61 \times 10^{3}$ & $<0,001$ \\
\hline P.A.(\%) & 33 & 68,82 & $|6,2|$ & 20 & 67,60 & 17,33 & 24 & 62,88 & 13,94 & 32 & 87,16 & 9,17 & $<0,001$ \\
\hline $\begin{array}{l}\text { Iron (mg// } 00 \\
\mathrm{ml})\end{array}$ & 33 & 98,15 & 30,22 & 20 & 99,20 & 58,97 & 22 & 128,45 & 54,76 & 31 & 66,45 & 32,22 & $<0,001$ \\
\hline $\begin{array}{l}\text { Fasting } \\
\text { glycaemia (mg/ } \\
\text { dl) }\end{array}$ & 33 & 102,97 & 25,72 & 20 & 126,75 & 62,57 & 24 & 117,67 & 48,70 & 32 & 94,84 & 10,01 & 0,003 \\
\hline AST (IU/I) & 33 & 20,42 & 10,46 & 20 & 36,70 & 19,30 & 24 & 58,33 & 30,52 & 32 & 12,75 & 5,44 & 0,001 \\
\hline ALT (IU/I) & 33 & $|7,2|$ & 8,03 & 20 & 46,95 & 42,24 & 24 & 66,08 & 37,40 & 32 & 13,25 & 9,31 & $<0,001$ \\
\hline AST/ALT & 33 & 1,29 & 0,59 & 20 & 0,91 & 0,34 & 24 & 0,96 & 0,40 & 32 & 1,20 & 0,61 & 0,026 \\
\hline $\begin{array}{l}\text { Total } \\
\text { bilirrubin (mg/ } \\
\text { dl) }\end{array}$ & 33 & $\mathrm{I}, 42$ & 1,11 & 20 & $\mathrm{I}, 40$ & 1,16 & 24 & $\mathrm{I}, 75$ & 0,95 & 32 & 0,77 & 0,38 & $<0,001$ \\
\hline $\begin{array}{l}\text { Alpha- } \\
\text { fetoprotein } \\
\text { (IU/I) }\end{array}$ & 33 & 3,90 & 2,50 & 19 & 5,56 & 3,86 & 23 & 13,47 & 10,87 & 31 & 3,71 & 2,54 & $<0,001$ \\
\hline $\begin{array}{l}\text { Serum } \\
\text { Albumin }(g / d l)\end{array}$ & 33 & 4,19 & 0,53 & 20 & 3,85 & 0,39 & 24 & 3,81 & 0,57 & 32 & 4,49 & 0,35 & $<0,001$ \\
\hline
\end{tabular}

Where: $N=$ number of cases; $M=$ mean number; $S D=$ standard deviation; $\mathrm{HCV}=$ Hepatitis $C$ Virus. Reference values: $\mathrm{N}^{\circ}$ of platelets $/ \mathrm{mm}^{3}:(140-$ $\left.450 \times 10^{3}\right)$; P.A.: (70 - 100), Iron (50 - 100); AST and ALT: (18); Total bilirrubin: (0.2 - 1.0); alpha-fetoprotein: (10); Albumin: (3.5 - 5.0). 


\section{Results}

Upon analysis of small groups of cirrhotic patients of different aetiologies we could demonstrate both haematological and biochemical distinctions, separating alcoholic and viral aetiologies.

Table 1 shows the haematological and biochemical data that distinguished the cirrhotic groups. The HCV group presented higher levels of iron, aminotransferases, total bilirrubin and alpha-fetoprotein, in addition to significantly lower platelets' counting and serum albumin levels. Furthermore, the ALC+HCV group presented significantly higher glycaemia as compared to cirrhosis of other aetiologies, as is showed in Table 2.

The anthropometric parameters as well as their uni- and multivariate analysis for the four groups are presented in Table 3 and 4. The HCV group has shown significantly higher $\mathrm{CHI}$ values when compared to the ALC+HCV group, and a marginal difference in comparison to the ALC group, indicating a better nutritional status for the HCV group. Moreover, the associated group, ALC+HCV, has shown the lowest TSF mean values. It should be noted that the HCV was the only group nutritionally distinct from the other cirrhotic groups.

Table 5 shows the uni- and multivariate analysis of nutritional evaluation of the cirrhotic groups using: a) a nutritional evaluation indexes that correlates weight and height (BMI), b) a parameter to evaluate the muscular compartment (AMA), and c) a parameter that evaluates the lipidic compartment (AFA). It also shows that the HCV group had values quite different from other aetiologies of cirrhosis with mean values closer to those of the control group.

Table 2: Multiple comparison with significant results among different cirrhotic aetiologies

\begin{tabular}{|c|c|c|c|c|c|c|c|c|c|}
\hline \multirow[b]{2}{*}{ GROUPS } & \multicolumn{9}{|c|}{ PARAMETERS } \\
\hline & $\mathrm{N}^{\circ}$ Plat. & Iron & AST & ALT & AST/ALT & $\alpha$-feto & Albumin & Glic & $\begin{array}{l}\text { Total } \\
\text { bilirrubin }\end{array}$ \\
\hline $\begin{array}{l}\mathrm{ALCOHOL} \times \mathrm{ALCOHOL}+ \\
\mathrm{HCV} \times \mathrm{HCV}\end{array}$ & 0.04 & 0.03 & 0.0001 & 0.0001 & 0.01 & 0.0001 & 0.004 & & \\
\hline $\begin{array}{l}\mathrm{ALCOHOL} \times \mathrm{ALCOHOL}+ \\
\mathrm{HCV}\end{array}$ & & & 0.0001 & 0.0001 & 0.01 & & 0.01 & 0.02 & \\
\hline $\mathrm{ALCOHOL} \times \mathrm{HCV}$ & 0.01 & 0.01 & 0.0001 & 0.0001 & 0.02 & 0.0001 & 0.003 & & 0.03 \\
\hline $\mathrm{ALCOHOL}+\mathrm{HCV} \times \mathrm{HCV}$ & & 0.03 & 0.001 & 0.01 & & 0.0004 & & & \\
\hline
\end{tabular}

Where: $\mathrm{N}^{\circ}$ plat. $=\mathrm{N}^{\circ}$ of platelets; $\alpha$-feto $=$ alpha-fetoprotein; Glic. $=$ fasting glycaemia

Table 3: Results of anthropometric parameters of the nutritional evaluation in the four groups by univariate analysis.

\begin{tabular}{|c|c|c|c|c|c|c|c|c|c|c|c|c|c|}
\hline \multirow[t]{2}{*}{ PARAMETERS } & \multicolumn{3}{|c|}{ ALCOHOL } & \multicolumn{3}{|c|}{$\mathrm{ALCOHOL+HCV}$} & \multicolumn{3}{|c|}{$\mathrm{HCV}$} & \multicolumn{3}{|c|}{ CONTROL } & \multirow[t]{2}{*}{$\mathrm{P}$} \\
\hline & $\mathrm{N}$ & M & DP & $\mathrm{N}$ & $M$ & $\mathrm{DP}$ & $\mathrm{N}$ & $M$ & $\mathrm{DP}$ & $\mathrm{N}$ & M & DP & \\
\hline$\%$ IBM & 33 & 112.19 & 19.78 & 20 & 107.08 & 18.00 & 24 & 118.45 & 14.92 & 32 & 107.08 & 19.93 & 0.103 \\
\hline $\mathrm{BMI}\left(\mathrm{Kg} / \mathrm{m}^{2}\right)$ & 33 & 25.75 & 4.30 & 20 & 24.70 & 3.98 & 24 & 26.49 & 3.28 & 32 & 24.00 & 4.33 & 0.112 \\
\hline TSF & 33 & 9.36 & 5.42 & 20 & 9.25 & 3.27 & 24 & 11.79 & 3.12 & 32 & 12.88 & 5.92 & 0.004 \\
\hline$\%$ TSF deplet. & 33 & 71.15 & 39.46 & 20 & 71.67 & 24.87 & 24 & 76.13 & 18.78 & 32 & 83.35 & 32.75 & 0.406 \\
\hline AMC & 33 & 26.36 & 2.76 & 20 & 26.22 & 2.64 & 24 & 26.07 & 3.17 & 32 & 24.93 & 2.93 & 0.195 \\
\hline$\%$ AMC deplet. & 33 & -4.44 & $12.5 \mid$ & 20 & -3.28 & 12.91 & 24 & -10.19 & 14.20 & 32 & -4.33 & 10.79 & 0.217 \\
\hline AMA $\left(\mathrm{mm}^{2}\right)$ & 33 & $\begin{array}{l}6.458 .8 \\
9\end{array}$ & 3.105 .85 & 20 & $\begin{array}{l}6.235 .1 \\
5\end{array}$ & 2.933 .54 & 24 & 7.254 .22 & 3.372 .00 & 32 & 5.794 .70 & 2.536 .05 & 0.343 \\
\hline AFA $\left(\mathrm{mm}^{2}\right)$ & 33 & -869.33 & 2.013 .75 & 20 & -712.69 & I.857.64 & 24 & -1.768 .83 & 2.155 .96 & 32 & -784.14 & I.442.7| & 0.170 \\
\hline $\mathrm{CHI}$ & 31 & 61.59 & 21.00 & 20 & 55.50 & 25.57 & 23 & 80.44 & 45.90 & 29 & 103.27 & 44.97 & 0.001 \\
\hline
\end{tabular}

Where: \% IBW = percentage of ideal body weight; BMI = body mass index; AMC = arm muscle circunference; $\%$ AMC deplet. = percentage of $A M C$

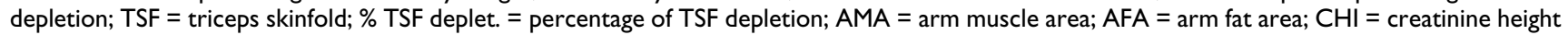
index. Note: The ALC+HCV group presented the lowest TSF mean values, while the HCV group showed the highest values for $\mathrm{CHI}$. In the multivariate analysis, only HCV group was nutritionally distinct from other cirrhotic group. 
Table 4: Results of the uni and multivariate analysis of the anthropometric parameters on the nutritional evaluation of cirrhotic groups.

\begin{tabular}{|c|c|c|c|c|c|c|c|c|c|c|}
\hline \multicolumn{11}{|l|}{ Univariate Analysis } \\
\hline Hypothesis & IBW & BMI & AMC & $\begin{array}{l}\text { AMC } \\
\text { deplet. }\end{array}$ & TSF & $\begin{array}{l}\text { TSF } \\
\text { deplet. }\end{array}$ & AMA & AFA & $\mathrm{CHI}$ & $\begin{array}{l}\text { Multivariat } \\
\text { e Analysis }\end{array}$ \\
\hline Four equal groups & 0.103 & 0.112 & 0.195 & 0.217 & 0.004 & 0.406 & 0.343 & 0.170 & 0.001 & 0.001 \\
\hline $\begin{array}{l}\text { Three equal cirrhotic } \\
\text { groups }\end{array}$ & & & & & 0.019 & & & & 0.059 & 0.001 \\
\hline$A L C=A L C+V H C$ & & & & & 0.027 & & & & 0.557 & 0.771 \\
\hline $\mathrm{ALC}=\mathrm{HCV}$ & & & & & 0.648 & & & & 0.061 & 0.001 \\
\hline $\mathrm{ALC}+\mathrm{HCV}=\mathrm{HCV}$ & & & & & 0.006 & & & & 0.026 & 0.002 \\
\hline
\end{tabular}

Where: \% IBW = percentage of ideal body weight; $\mathrm{BMI}=$ body mass index; $\mathrm{AMC}=$ arm muscle circunference; \% $\mathrm{AMC}$ deplet. = percentage of $\mathrm{AMC}$ depletion; TSF = triceps skinfold; $\%$ TSF deplet. = percentage of TSF depletion; $A M A=$ arm muscle area; $A F A=$ arm fat area; $C H I=$ creatinine height index.

Table 5: Uni and multivariate analysis of the anthropometric parameters of general evaluation (BMI) and muscular (AMA) and lipidic (AFA) compartments.

\begin{tabular}{|c|c|c|c|c|}
\hline \multicolumn{5}{|l|}{ UNIVARIATE ANALYSIS } \\
\hline HYPOTHESIS & BMI & AMA & AFA & $\begin{array}{l}\text { MULTIVARIATE } \\
\text { ANALYSIS }\end{array}$ \\
\hline FOUR EQUAL GROUPS & 0,112 & 0,343 & 0,170 & 0,001 \\
\hline $\begin{array}{l}\text { THREE EQUAL } \\
\text { CIRRHOTIC GROUPS }\end{array}$ & & & & 0,001 \\
\hline $\mathrm{ALC}=\mathrm{ALC}+\mathrm{HCV}$ & & & & 0,812 \\
\hline $\mathrm{ALC}=\mathrm{HCV}$ & & & & 0,001 \\
\hline $\mathrm{ALC}+\mathrm{HCV}=\mathrm{HCV}$ & & & & 0,001 \\
\hline $\mathrm{ALC}=\mathrm{CONTROL}$ & & & & 0,001 \\
\hline $\mathrm{ALC}+\mathrm{HCV}=\mathrm{CONTROL}$ & & & & 0,003 \\
\hline $\mathrm{HCV}=\mathrm{CONTROL}$ & & & & 0,089 \\
\hline
\end{tabular}

Note: The HCV group, with no alcohol, was significantly different from other aetiologies being closer to the control group.

Table 6: Humoral-immunological parameters of the four studied groups.

\begin{tabular}{|c|c|c|c|c|c|c|c|c|c|c|c|c|c|}
\hline \multirow[t]{2}{*}{ PARÂMETERS } & \multicolumn{3}{|c|}{ ALCOHOL } & \multicolumn{3}{|c|}{$\mathrm{ALCOHOL}+\mathrm{HCV}$} & \multicolumn{3}{|c|}{$\mathrm{HCV}$} & \multicolumn{3}{|c|}{ CONTROL } & \multirow[t]{2}{*}{$P$} \\
\hline & $N$ & $M$ & SD & $N$ & $M$ & SD & $N$ & $M$ & SD & $N$ & $M$ & SD & \\
\hline $\mathrm{C}_{3}(\mathrm{mg} \%)$ & 33 & 106.48 & 42.72 & 20 & 92.62 & 33.72 & 24 & 79.33 & 26.42 & 32 & 123.19 & 33.16 & $<0.001$ \\
\hline $\mathrm{C}_{4}(\mathrm{mg} \%)$ & 33 & 20.79 & 8.12 & 20 & 19.70 & 8.57 & 24 & $|4.2|$ & 4.66 & 32 & 26.84 & 7.75 & $<0.001$ \\
\hline Gammaglobulin (g\%) & 33 & 1.54 & 0.39 & 20 & 2.04 & 0.41 & 24 & 2.28 & 0.76 & 32 & 1.35 & 0.28 & $<0.001$ \\
\hline $\operatorname{lgA}(\mathrm{mg} / \mathrm{dl})$ & 30 & 577.27 & 286.26 & 20 & 519.15 & 203.92 & 23 & 505.39 & 314.59 & 32 & 268.94 & 121.05 & $<0.001$ \\
\hline $\lg M(\mathrm{mg} / \mathrm{dl})$ & 30 & 238.33 & 146.46 & 20 & 248.20 & 96.10 & 23 & 325.70 & 222.32 & 32 & 170.03 & 69.25 & 0.001 \\
\hline $\lg G(\mathrm{mg} / \mathrm{dl})$ & 30 & I.775.87 & 464.42 & 20 & 2.352 .10 & 496.62 & 23 & 2.643 .96 & 907.37 & 32 & 1.594 .88 & 379.22 & $<0.001$ \\
\hline $\operatorname{lgE}(\mathrm{IU} / \mathrm{dl})$ & 29 & 5.80 & 0.98 & 18 & 4.83 & 1.18 & 18 & 3.78 & 0.81 & 32 & 4.65 & 1.38 & $<0.001$ \\
\hline
\end{tabular}

Where: $C_{3}$ and $C_{4}$ are serum complement components 3 and 4, respectively; $\lg A$, $\lg M$, $\lg G$ and $\lg E$ are immunoglobulins $A, M, G$ and $E$, respectively. Range for reference values: $C_{3}$ (74-185); $C_{4}(16-44)$; Gammaglobulin (0.8 - I.6); IgA (I53 - 359); IgM (73 - I7I); IgG (952 - I538); IgE (up to I00). 
Table 7: Multiple comparisons with significant results among various aetiologies of cirrhosis.

\begin{tabular}{|c|c|c|c|c|c|c|}
\hline \multirow[t]{2}{*}{ GROUPS } & \multicolumn{6}{|c|}{ PARAMETERS } \\
\hline & $\mathrm{C}_{3}$ & $\mathrm{C}_{4}$ & Gamma globulin & $\lg M$ & $\lg G$ & $\lg E$ \\
\hline $\begin{array}{l}\mathrm{ALC} \times \mathrm{ALC}+ \\
\mathrm{HCV} \times \mathrm{HCV}\end{array}$ & 0.01 & 0.004 & 0.0001 & 0.06 & 0.0001 & 0.0001 \\
\hline $\begin{array}{l}\mathrm{ALC} \times \mathrm{ALC}+ \\
\mathrm{HCV}\end{array}$ & & & 0.0001 & & 0.0008 & 0.005 \\
\hline $\mathrm{ALC} \times \mathrm{HCV}$ & 0.004 & 0.001 & 0.0001 & 0.02 & 0.0001 & 0.0001 \\
\hline $\begin{array}{l}\mathrm{ALC}+\mathrm{HCV} \times \\
\mathrm{HCV}\end{array}$ & & 0.01 & & 0.07 & & 0.007 \\
\hline
\end{tabular}

Where: $A L C=$ alcohol; $\mathrm{HCV}=$ Hepatitis $C$ Virus; $C_{3}$ and $C_{4}$ are serum complement components 3 and 4 , respectively; IgM, IgG and IgE are immunoglobulins $M, G$ and $E$, respectively.

Table 8: Immunological results of cellular parameters in the four studied groups.

\begin{tabular}{|c|c|c|c|c|c|c|c|c|c|c|c|c|c|}
\hline \multirow[t]{2}{*}{ PARÂMETERS } & \multicolumn{3}{|c|}{ ALCOHOL } & \multicolumn{3}{|c|}{$\mathrm{ALCOHOL}+\mathrm{HCV}$} & \multicolumn{3}{|c|}{$\mathrm{HCV}$} & \multicolumn{3}{|c|}{ CONTROL } & \multirow[t]{2}{*}{$P$} \\
\hline & $\mathrm{N}$ & $M$ & SD & $N$ & $M$ & SD & $\mathrm{N}$ & M & SD & $N$ & $M$ & SD & \\
\hline $\begin{array}{l}\text { Leukocytes/ } \\
\mathrm{mm}^{3}\end{array}$ & 33 & 5.890 .91 & 1.740 .04 & 20 & 5.980 .00 & 2.694 .80 & 24 & 4.966 .67 & I.705.40 & 32 & 6.987 .50 & 1.885 .04 & 0.003 \\
\hline $\begin{array}{l}\text { Lymphocytes/ } \\
\mathrm{mm}^{3}\end{array}$ & 33 & I.527.36 & 593.11 & 20 & 1.929 .10 & I.167.07 & 24 & I.535.7| & 725.34 & 32 & 2.027 .75 & 619.94 & 0.021 \\
\hline $\mathrm{CD}_{4}^{+} / \mathrm{ul}$ & 32 & 664.44 & 291.94 & 19 & 777.16 & 450.14 & 20 & 663.85 & 310.07 & 26 & 762.54 & 232.89 & 0.460 \\
\hline $\mathrm{CD}_{8}^{+} / \mathrm{ul}$ & 32 & 297.03 & 200.15 & 19 & 387.00 & 335.10 & 20 & 337.60 & $315.4 \mid$ & 26 & 439.73 & 149.79 & 0.169 \\
\hline $\mathrm{CD}_{4}^{+} / \mathrm{CD}_{8}{ }^{+}$ & 32 & 2.70 & 1.27 & 19 & 2.56 & 1.08 & 20 & 2.50 & 1.08 & 26 & 1.94 & 0.84 & 0.064 \\
\hline
\end{tabular}

Where: $\mathrm{N}^{\circ}=$ number of cases; $\mathrm{M}=$ mean number; $\mathrm{SD}=$ standard deviation; $\mathrm{ALC}=$ alcohol; $\mathrm{HCV}=$ Hepatitis $\mathrm{C}$ Virus. Reference values: $\mathrm{N}^{\circ}$ of leukocytes $/ \mathrm{mm}^{3}\left(5-10 \times 10^{3}\right) ; \mathrm{N}^{\circ}$ of lymphocytes $/ \mathrm{mm}^{3}\left(\mathrm{I}-3 \times 10^{3}\right) ; C D 4^{+}(355-1298) ; \mathrm{CD}^{+}(144-796)$.

Table 9: Responses to intradermic tests of delayed hypersensitivity from the four studied groups.

\begin{tabular}{lllll}
\hline GROUPS & $\mathrm{N}$ & $\begin{array}{l}\text { TWO OR MORE } \\
\text { POSITIVE TESTS }\end{array}$ & ONE POSITIVE TEST & NO POSITIVE TEST \\
\hline ALCOHOL (\%) & 32 & $22(68.75)$ & $2(6.25)$ & $8(25.00)$ \\
ALCOHOL + HCV (\%) & 20 & $17(85.00)$ & $2(10.00)$ & $1(5.00)$ \\
HCV (\%) & 24 & $14(58.33)$ & $8(33.34)$ & $2(8.33)$ \\
CONTROL (\%) & 32 & $26(85.25)$ & $6(18.75)$ & $0(0.00)$ \\
\hline
\end{tabular}

$\mathrm{P}<0.001$

The analysis of humoral immunological parameters (Table 6) reveals that the HCV group presents the lowest mean values for the $\mathrm{C} 3$ and $\mathrm{C} 4$ among the cirrhotic groups. It is also shown that for those groups infected with HCV the gamma globulin mean values were significantly higher than those for the Alcohol group. Regarding the immunoglobulins IgM and IgG, all of the HCV-related groups have shown mean values significantly higher than have the alcohol group. On the other hand, the Alcohol group had the higher IgE values as compared to the other aetiologies of cirrhosis, as is presented in Table 7 .

Table 8 shows that while the number of leukocytes and lymphocytes in peripheral blood of cirrhotic patients were significantly lower as compared with the control group, counting of the leukocytes/ lymphocytes did not allow discrimination between the various aetiologies of cirrhosis. Counting of the lymphocytes sub-population CD4+ 
and CD8+ did not distinguish a single studied group, not even the control, either in the uni. or the multivariate analysis. Only the CD4+/CD8+ ratio was higher for cirrhotic - than control groups.

The analysis of the cirrhotic groups regarding their response to intradermic tests of delayed hypersensitivity is shown in Table 9. It can be seen that the alcohol group displayed a significantly higher percentage of anergic patients than other studied groups $(\mathrm{p}<0.001)$; this pattern was preserved even if the control group was excluded from the analysis ( $\mathrm{p}=0.02)$. The HCV group, in turn, showed the highest percentage of immunodeficient patients.

\section{Discussion}

The novelty and major contribution of the present study is to open the possibility of discriminating the main different aetiologies of cirrhosis according to nutritional and immunological parameters. The patients with alcoholic cirrhosis in the initial compensated form of the disease show already some degree of malnutrition, as revealed by the different nutritional parameters described by various authors [2,9,25-27].

On the other hand, the HCV-cirrhotic group has shown better values for nutritional parameters, despite the concomitant and conspicuous biochemical alterations. Therefore, it was not possible to correlate higher levels of aminotransferases and bilirrubin, as well as the lower levels of albumin and platelets, with the observed nutritional alterations.

The CHI is probable the most widely used index for evaluating body muscle mass [7], as it correlates with oxygen consumption and lean muscle mass [23]. The CHI was more elevated in the HCV group, showing no association with gender and other parameters used for the evaluation of the muscular compartment, similar to the study of Caregaro and collaborators (1996).

Mean values of TSF being significantly lower in the $\mathrm{ALC}+\mathrm{HCV}$ group can be interpreted as very specific in the estimation of the fat compartment, since this index is not influenced by liquid retention [28]. Contrariwise, in this same group (ALC+HCV), the other index that allegedly evaluates the fat compartment, named arm fat area (AFA) [19], has not shown a significant alteration in this aetiologic group; as it was also observed by others [29].

As the presence of ascites and/or edema may interfere in the nutritional evaluation of cirrhosis, a special care was taken in terms of excluding such patients from the study, similarly to what was made by other authors $[25,28,30]$.
It is well known that nutritional status does exert an influence in all aspects of immunity, including humoral response, phagocytosis, complement components and, specially, cellular mediated response. As a rule, the effect of caloric and protein depletion in the organism is to suppress or decrease the immune response, although in certain cases malnutrition stimulate immune response. This can be observed, particularly, in the humoral response of patients with alcoholic liver disease or in the response to infections of undernourished patients [31]. The exaggerated humoral response does not mean a higher degree of protection; on the contrary, it is rather a reflex of the dysfunction of the regulatory and stimulatory factors of the immune system [14].

Similarly to the nutritional evaluation, the immunological parameters in the course of cirrhosis were preferentially evaluated in alcoholic aetiology [2,12,32-34]. In our comparative study, the behavior of the lymphocytes mediating the nutritional and immunological alterations was similar in alcoholic and HCV groups. A possible explanation for this similarity in the lymphocyte counting may be due to the fact that the better nutritional state is compensated with the higher immunological alteration and vice-versa in the HCV and alcoholic aetiologies, respectively.

Among the evaluated immunological parameters, there has been observed the decrease in the complement components, fraction 4 in particular, associated with the opsonic and bactericide activity of the cirrhotic sera [3537]. One could then speculate that lower levels of $\mathrm{C} 4$ would lead to higher frequency of infectious processes.

One of the most common immunological alterations in cirrhotic patients is the occurrence of hypergammaglobulinemia [38], with variable increase in IgG, IgA and IgM in different hepatic disorders [39]. In patients with alcoholic cirrhosis there has been shown elevated levels of IgA and IgG [40-42], and normal IgM [42]. Contrariwise, we have observed equal levels of IgG in the alcoholic-cirrhotic and control groups, and elevated levels of IgG and IgM in the HCV-cirrhotic patients. Since many of the former studies with alcoholic cirrhosis were carried out before the HCV detection, it is difficult to rule out an eventual aetiologic association. The elevated levels of IgM and IgG in HCV cirrhosis, described by Sarin and collaborators (1997), could be due to the dysfunction of the T cells, currently taken as responsible for the virus persistence, as well as the severity of the hepatic disease [43]. The elevated levels of IgM found in the HCV group in our study corroborate with Sarin's et al findings [17].

The increase in the IgE levels, however, cannot be associated with severity of the chronic liver disease. As others 
[44], we observed the elevation of this fraction in the alcoholic aetiology, but its significance is not clear. It is interesting to note, however, that the degree of malnutrition and anergy was higher in this very group, factors that may influence the levels of IgE $[44,45]$.

The reduction in the number of lymphocytes and the depression in the response to the intradermic tests peculiar to a delayed hypersensitivity seem to be directly related to the severity of liver damage [1,46-48]. In our study, there was no discrimination among the different aetiologies of cirrhosis according to the lymphocyte subpopulations, CD4+ and CD8+, as seen by others [65]. Even though, the $\mathrm{CD} 4 / \mathrm{CD} 8$ ratio has distinguished the cirrhotic group from the control patients, what had been reported for the alcoholic aetiology of cirrhosis [49].

Intradermic test of delayed hypersensitivity with higher percentages of anergy have been described by many authors in alcoholic cirrhosis $[1,2,12,33]$. Anergy was found more frequently among alcoholic patients, albeit poor intradermic response was equally frequent in HCV and alcohol groups, differently from other findings [16]. It is important to point out that the immunodeficiency of the HCV group was not associated with higher degrees of malnutrition, except for the lower mean values of the albumin which has been related to the anergy of the intradermic tests [12].
The most noticeable laboratorial alterations of the HCV group could be related to a deficient cellular immune response. This non-nutritional factor may probably be connected with the severity of the hepatocellular lesion or to immunological alterations triggered by the HCV. These hypotheses demand further investigations to be confirmed.

\section{List of Abbreviations}

$\%$ IBW, percentage of ideal body weight; BM index, body mass índex; TSF, triceps skinfold; \% TSF, percentage of the standard value for triceps skinfold; AMC, arm muscle circunference; AMA, arm muscle area; AFA, arm fat area; $\mathrm{CHI}$, creatinine-height index; CD4+and CD8+, lymphocytes subpopulations, HCV, hepatite C virus; ALC, alcoholic cirrhosis; ALC+HCV, cirrhosis due to alcohol plus HCV virus; IgA, IgM, IgG and IgE, immunoglobulins A, M, G and E.

\section{Competing Interests}

None declared.

\section{Contribution of Authors}

WRC: conceived of the study, participated in its design, nutritional and immunological evaluation, filling in the protocols and writing the manuscript, ES: design of the study, coordination, writing and editing the manuscript, FJC: design of the study and data analysis AAL: design of the study.

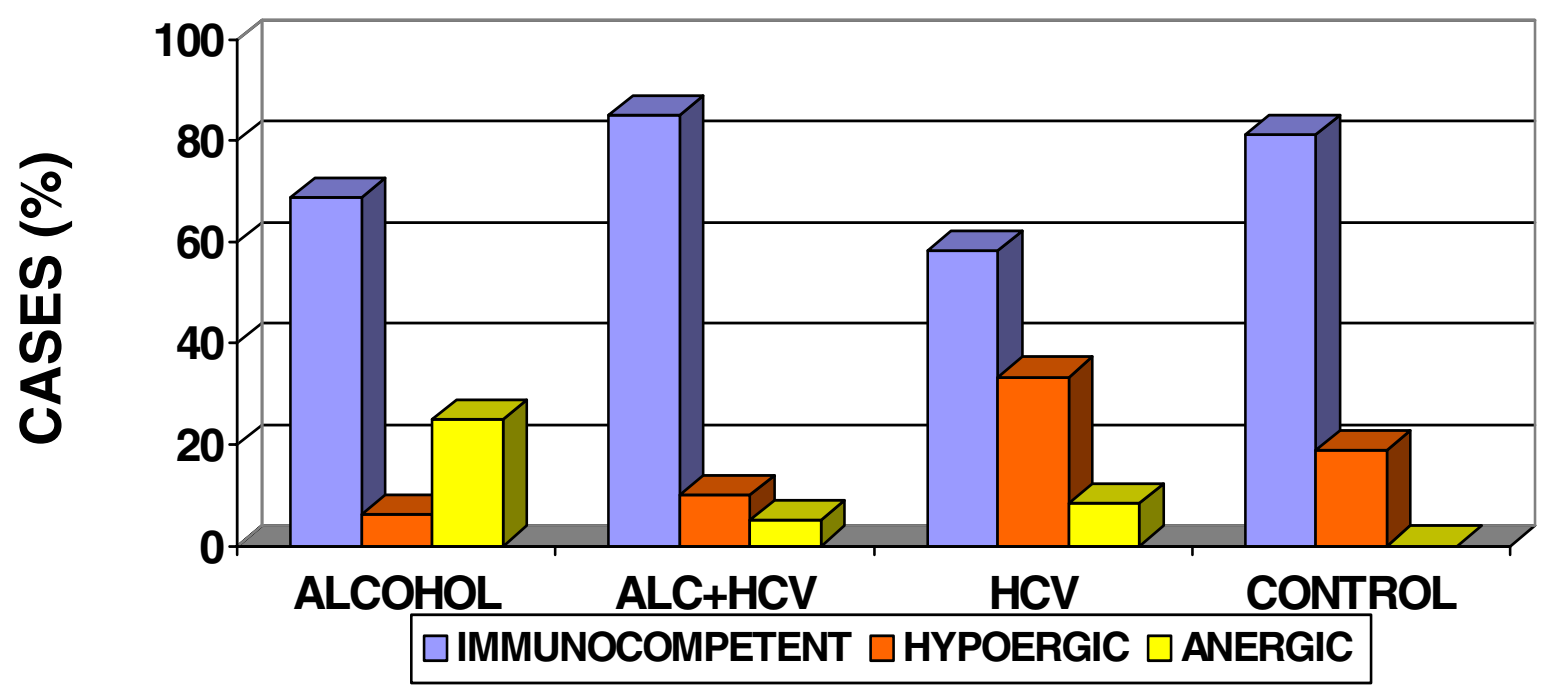

Figure I

Percentage of immunocompetent, hypoergic and anergic patients according to the intradermic tests of delayed hypersensitivity in the four studied groups. 


\section{References}

I. Franco D, Belghiti J, Cortesse A, Boucquey BM, Charra M, Lacaine F and Bismuth $\mathrm{H}$ : Nutrition et immunité du cirrhotique alcoolique. Gastroenterol Clin Biol 198I, 5:839-846.

2. Mendenhall CL, Anderson S, Weesner RE, Goldberg SJ and Crolic KA: Protein-calorie malnutrition associated with alcoholic hepatitis. Amer J Med 1984, 76:2 I I-222.

3. Mezey E: Interaction between alcohol and nutrition in the pathogenesis of alcoholic liver disease. Semin Liver Dis 1991, I I:340-348.

4. Mezey E: Alcoholic liver disease: roles of alcohol and malnutrition. Am J Clin Nutr 1980, 33:2709-27।8.

5. Lieber CS: Alcohol and the liver: 1994 update. Gastroenterology 1994, I06: 1085-I I05.

6. Müller MJ: Malnutrition in cirrhosis. J Hepatol 1995, 23:3 I-35.

7. Crawford DHG, Cuneo RC and Shepherd RW: Pathogenesis and assessment of malnutrition in liver disease. J Gastroent Hepatol 1993, 8:89-94.

8. Müller MJ, Pirlich M, Balks $\mathrm{HJ}$ and Selberg O: Glucose intolerance in liver cirrhosis: Role of hepatic and non-hepatic influences. J Clin Chem Biochem 1994, 32:749-758.

9. Lautz HU, Selberg O, Körber J, Bürger M and Müller MJ: Protein-calorie malnutrition in liver cirrhosis. Clin Investig 1992, 70:478-486.

10. Caly WR and Strauss E: A prospective study of bacterial infections in patients with cirrhosis. J Hepatol 1993, 18:535-558.

II. Scrimshaw NS, Taylor CE and Gordon JE: Interactions of nutrition and infection. Am J Med Sci 1959, 237:367-403.

12. O'Keefe SJ, EL-Zayadi AR, Carraher TE and Davis M: Malnutrition and immuno-incompetence in patients with liver disease. Lancet 1980, 20:615-617.

13. Chandra RK: 1990 McCollum award lecture. Nutrition and immunity: Lessons from the past and new insights into the future. Am J Clin Nutr 1991, 53:1087-1 I0I.

14. Mendenhall CL: Immunity, malnutrition, and alcohol. Alcohol Health \& Research World 1992, 16:23-28.

15. Mainous MR and Deitch EA: Nutrition and infection. Surg Clin North Am 1994, 74:659-676.

16. Caregaro L, Alberino F, Amodio P, Merkel C, Bolognesi M, Angeli P and Gatta $A$ : Malnutrition in alcoholic and virus-related cirrhosis. Am J Clin Nutr 1996, 63:602-609.

17. Sarin AK, Dhingra N, Bansal A, Malhotra S and Guptan RC: Dietary and nutritional abnormalities in alcoholic liver disease: $A$ comparison with chronic alcoholics without liver disease. Am J Gastroent 1997, 92:777-783.

18. Garcia-Tsao G, Groszmann RJ, Fisher RL, Conn HO, Atterbury CE and Glickman M: Portal pressure, presence of gastroesophageal varices and variceal bleeding. Hepatology 1985, 5:419-424.

19. Frisancho AR: New norms of upper limb fat and muscle areas for assessment of nutritional status. Am J Clin Nutr 1981, 34:2540-2545.

20. Frisancho AR: New standards of weight and body composition by frame size and height for assessment of nutritional status of adults and the elderly. Am J Clin Nutr 1984, 40:808-819.

21. Blackburn GL, Bistrian BR, Maini BS, Schlamm HT and Smith MF: Nutritional and metabolic assessment of the hospitalized patient. J Parenter Enter Nutr 1977, I : I I-22.

22. Heetderks JE: The comprehensive nutritional assessment. Nutritional Support. Theory and therapeutics Edited by: Shikora AS and Blackburn GL. Chapman and Hall series in clinical nutrition; 1996:30-53.

23. Blackburn GL and Thornton PA: Nutritional assessment of the hospitalized patient. Med Clin North Am 1979, 63:103-I I I5.

24. Catalona WJ, Taylor PT, Rabson AS and Chretien PB: A method for dinitrochlorobenzene contact sensitization. A clinical pathological study. N Engl J Med 1972, 286:399-402.

25. Prijatmoko D, Strauss BJG, Lambert JR, Sievert W, Stroud DB, Wahlqvist ML, Katz B, Colman J, Jones P and Korman MG: Early detection of protein depletion in alcoholic cirrhosis: Role of body composition analysis. Gastroenterology 1993, I 05: 1839-1845.

26. Crawford HG, Shepherd RW, Halliday JW, Cooksley GWE, Golding $D$, Cheng WSC and Powell LW: Body composition in nonalcoholic cirrhosis: the effect of disease etiology and severity on nutrional compartments. Gastroenterology 1994, 106:1611-1617.

27. Merli M, Riggio $O$ and Capocaccia L: Nutritional status in cirrhosis. J Hepatol 1994, 2 1:317-325.
28. Madden A and Morgan MY: A comparison of skinfold anthropometry and bioeletrical impedance analysis for measuring percentage body fat in patients with cirrhosis. J Hepatol 1994 , $21: 878-883$.

29. Loguercio C, Sava E, Marmo R, Del Vecchio Blanco C and Coltorti M: Malnutrition in cirrhotic patients: anthropometric measurements as a method of assessing nutritional status. $\mathrm{Br} J \mathrm{Clin}$ Pract 1990, 44:98-101.

30. Morgan MY and Madden AM: The assessment of body composition in patients with cirrhosis. Eur J Nucl Med 1996, 23:213-225.

31. Gross RL and Newberne PM: Role of nutrition in immunologic function. Physiological Reviews 1980, 60:188-302.

32. Liu YK: Effects of alcohol on granulocytes and lymphocytes. Semin Hematol 1980, I 7: I30-136.

33. Mills PR, Shenkin A, Anthony RS, McLelland AS, Main ANH, MacSeen RNM, Path FRC and Russell RI: Assessment of nutritional status and in vivo immune response in alcoholic liver disease. $\mathrm{Am} \mathrm{J}$ Clin Nutr 1983, 38:849-859.

34. Müller $\mathrm{C}$, Wolf $\mathrm{H}$, Göttlicher $\mathrm{J}$ and Eibl MM: Helper-inducer and supressor - inducer lymphocyte subsets in alcoholic cirrhosis. Scand J Gastroenterol I99I, 26:295-30I.

35. Rimola A, Soto R, Bory F, Arroyo V, Piera C and Rodés J: Reticuloendothelial system phagocytic activity in cirrhosis and its relation to bacterial infections and prognosis. Hepatology 1984, 4:53-58.

36. Rimola A: Infecções bacterianas en la cirrosis hepatica. MTAMedicina Interna 1987, 5: 161-224.

37. Akalin HE, Laleli $Y$ and Telatar $\mathrm{H}$ : Serum bactericidal and opsonic activities in patients with non-alcoholic cirrhosis. Quartely J Med 1985, 56:431-437.

38. Trigger DR and Wright R: Hyperglobulinaemia in liver disease. Lancet 1973, 30: |494-|496.

39. Sherlock S: Hepatic cirrhosis. In: Diseases of the liver and biliary system Tenthth edition. Edited by: Sherlock S and Dooley J. Oxford: Blackwell Science Ltd; 1997:37I-384.

40. Gluud C, Tage-Jensen U, Rubinstein E and Henriksen JH: Autoantibodies and immunoglobulin in patients with alcoholic cirrhosis. Digestion 1984, 30: I-6.

41. Allison MED and Hodgson HJF: Regulation of peripheral blood Bcell IgA production in alcoholic cirrhosis. J Clin Lab Immunol 1989, 30: I27-I30.

42. Girón JÁ, Alvarez-Mons M, Menéndez-Caro JL, Abreu L, Albillos A, Manzano $L$ and Durántez $A$ : Increased spontaneous and lymphokine-conditioned IgA and IgG synthesis by cells from alcoholic cirrhotic patients. Hepatology 1992, 16:664-670.

43. Zhi Qiang Yao, Nguyen DT, Hiotellis Al and Hahn YS: Hepatitis C virus core protein inhibits human $T$ ymphocyte responses by a complement - Dependent regulatory pathway. J Immunol 2001, 167:5264-5272.

44. Vidal C, Quintela AG, Millan I, Gude F and Cuervas-Mons V: Serum IgE levels in liver cirrhosis. Contrasting results in alcoholic and non-alcoholic patients. Clin Exp Immunol 1994, 24:540-548.

45. Smith WI, Van Thiel DH, Whiteside T, Janoson B, Magovern J, Puet T and Rabin BS: Altered immunity in male patients with alcoholic liver disease: Evidence for defective immune regulation. Alcohol Clin Exp Res 1980, 4:199-206.

46. Sobhonslidsuk A, Roongpisuthipong C, Nantiruj K, Kulapongse S, Songchitsomboon S, Sumalnop K and Bussagorn N: Impact of liver cirrhosis on nutritional and immunological status. J Med Assoc Thai 2001, 84:982-988.

47. Rodríguez Félix L, Martín Santana A, Gutiérrez Fernández J and Zamora-Madaria E: Alteraciones de la inmunidad celular, estado de nutrición y déficit de zinc en la cirrosis hepática etílica. Rev Clin Esp 1987, 180:496-501.

48. Lombardo L, Capaldi A, Poccardi G and Vineis P: Peripheral blood CD3 and CD4 T-lymphocyte reduction correlates with severity of liver cirrhosis. Int J Clin Lab Res 1995, 25: I 53-I 56.

49. Couzigou P, Vincendeau P, Fleury B, Richard-Molard B, Perron A, Bergeron J-L, Bezian JH, Amouretti $M$ and Béraud $C$ : Étude des modifications des sous-populations lymphocytaires circulantes au cours des hépatopathies alcooliques. Rôle respective de l'alcool, de l'insuffisance hépato-cellulaire et de la dénutrition. Gastroenterol Clin Biol 1984, 8:915-919. 